\title{
Perception of eye drops self-instillation in the elderly with or without facial support device
}

\author{
Percepção de autoinstilação de gotas oculares em idosos \\ com ou sem dispositivo de apoio facial
}

Ana Luiza Fontes de Azevedo Costa', Thiago Gonçalves dos Santos Martins', Thomaz Gonçalves dos Santos Martins², Paulo Schor ${ }^{1}$

\section{Dear editor,}

A large amount of eyedrops users have difficulty in instillation, often touching the tip of the bottle into the eye, which can lead to contamination of the product in the bottle. There is also excessive instillation of droplets, which generates waste and may cause poisoning. The use of the Eyedrop ${ }^{\circledR}$ facial supporter reduced the touch of the tip of the eyedrop bottle on the ocular tissues, making instillation easier. ${ }^{(1)}$

Studies show that most patients use their eyedrops incorrectly, which raises concerns, since the eyedrops is the main route of administration of ophthalmologic drugs. ${ }^{(2)}$

Patients with visual impairment are at greater risk of inappropriate use of eyedrops, as well as illiterate patients, who are still a substantial part of our patients. There is a need for a simplified system through which patients with glaucoma, for example, can identify and differentiate their many medications. ${ }^{(3)}$

We evaluated eyedrops from various brands and concluded that even when the patient's vision is preserved they can misuse the eyedrops, because despite the difference in the formulation, the bottles are very similar. The incorrect identification of the eyedrops leads to inadequate use, since the patient, besides being using a substance that may not be treating the disease, may be worsening his clinical condition. This mistake can also occur with medications given in drops, leading to severe eye burns due to inadequate $\mathrm{pH} .{ }^{(4)}$

Aiming to reduce the misuse of eyedrops, we developed eyedrops covers made from flexible material with different textures and scents, capable of being adapted to bottles from different laboratories. The idea is to facilitate the identification of eyedrops, allowing greater autonomy to users.

To test the efficacy of the covers, we randomly selected 31 healthy volunteers to take a test consisting of four different types of eyedrops in four different situations.

We evaluated a total of 31 volunteers, $42 \%$ male and $58 \%$ female, aged between 20 and 90 years. The hit rate, when the volunteers were blindfolded, was $19 \%$. This percentage increased with the use of special covers with different odors (94\%), texture (97\%) and both (99\%).

At the end of the study, we asked the volunteers what type of cover would be more useful for the proper identification of the eyedrops. Fifty-eight percent of participants preferred special covers with texture, $6 \%$ the cover with odors, and $36 \%$ the covers with both odors and textures. ${ }^{(4)}$

We noticed that the use of the covers facilitated the identification of the eyedrops, which could reduce the risk of misuse. Although the three cover types had a high recognition rate, most participants preferred only the covers with different textures. We concluded that we can still take advantage of the intact senses of patients with visual impairments and avoid undue identification of eyedrops. Inappropriate use of eyedrops is a problem that should be studied, but misidentification of the eyedrops to be used is also very harmful to the patient. ${ }^{(4)}$

\section{REFERENCES}

1. Portes AJ, Lopes RM, Cardoso MG, Fernades RA, Souza TA. Percepção de autoinstilação de gotas oculares em idosos com ou sem dispositivo de apoio facial. Rev Bras Oftalmol. 2016;75(6):447-51.

2. Kass MA, Hodapp E, Gordon M, Kolker AE, Goldberg I. Patient administration of eyedrops. Part 11. Observation. Ann Ophthalmol. 1982,14(9):889-93.

3. Labetoulle M, Frau E, Le Jeunne C. Systemic adverse effects of topical ocular treatments. Presse Med. 2005;34(8):589-95.

4. Costa AL, Martins TG, Schor P. Multisensory eyedrop bottle sleeves for better identificantion of eyedrops. Insight (San Francisco). 2016;41:16.

\section{Corresponding Author:}

Ana Luiza Fontes de Azevedo Costa,

Rua Botucatu, 821 Vila Clementino, São Paulo

Zip Code: 04023-062, Tel.: +552125712248

E-mail luizafacosta@hotmail.com

\footnotetext{
${ }^{1}$ Universidade Federal de São Paulo, São Paulo, SP, Brazil.

${ }^{2}$ Academic Course in Medicina, Universidade Estácio de Sá, Rio de Janeiro, RJ, Brazil.
}

The authors declare no conflicts of interests.

Received for publication 18/01/2017 - Accepted for publication 12/04/2017. 